\title{
The Effect of Age on Uniqueness, Simplicity and Aliveness among Old Age People
}

\author{
Dr. Chandrakant Jamadar ${ }^{1}$, Dr. Shankarlinge Gowda ${ }^{2}$, Dr. S. P. Melkeri ${ }^{3}$
}

\section{ABSTRACT}

The present study is an attempt to investigate the conjoint of impact of age on uniqueness, simplicity and aliveness among old age people. The sample consists of 210 old age people from Mysore old age home. In 210, 105 pensioned and 105 non pensioned old age people, the data collected in random method. The result shows that, significant differences in gender, domicile and dimensions of the behavior, also age is more effective role in changing uniqueness, simplicity and aliveness.

Keywords: Uniqueness, Simplicity, Aliveness, Peak Experience And Age

Old age" or the "elderly" are the terms, which are frequently used, both in popular usage and in academic environment to refer to those who are above 60 years. While everyone agrees that ageing is a normal, inevitable and universal phenomenon for biologists and medical scientists, ageing refers to and is measured as deterioration in physical capabilities; psychologists measure it as a decline in various adaptive capabilities. Later adulthood is the last major segment of the life span. Sixty-five has usually been cited as the dividing line between middle age and old age (Hareven, 1976). ''Gerontologists have attempted to deal with these age-related differences among the elderly by dividing later adulthood into two groups'? the young-old, from age 65 to 74 years, and the old-old, from 75 years and above (Hall, 1980). Our society tends to define old age mainly in terms of chronological age. In primitive societies, old age is generally determined by physical and mental conditions rather than by chronological age. Such a definition is more accurate than ours.

Everyone is not in the same mental and physical condition at age 65. Ageing is an individual process that occurs at different rates in different people, and psychosocial factors may retard or accelerate the physiological changes. It is said that the statuses and roles of older persons, their culture patterns, social organization and collective behavior are affected by social change. Ageing is, no doubt, a physiological phenomenon, which is accompanied by some complex progressive changes in an organism.

\footnotetext{
${ }^{1}$ Asst. Professor, Post Graduate Department of Studies in Psychology, Maharani's College for Women, Mysore

${ }^{2}$ Asst. Professor, Maharaja College, University of Mysore

${ }^{3}$ Professor and Chairman, Department of Psychology, Gulbarga University Gulbarga, Karnataka

*Responding Author

(C) 2015 I C Jamadar, S Gowda, S Melkeri; licensee IJIP. This is an Open Access Research distributed under the terms of the Creative Commons Attribution License (http://creativecommons.org/licenses/by/2.0), which permits unrestricted use, distribution, and reproduction in any Medium, provided the original work is properly cited.
} 


\section{The Effect of Age on Uniqueness, Simplicity and Aliveness among Old Age People}

Henderson (1952), "Old age is a natural and normal condition. Its pathologies are the same as those that occur at any other age period, but they are intensified by illness, family disorganization, unemployability, reduced income and dependency.”

Birrren and Renner (1977), well known psychologists refer to ageing as "the sum of regular changes that occur in mature genetically representative organisms living under representative environ Davidson (1984) opines that ageing comprises of those fundamental changes not due to disease occurring in individuals after maturity which are more or less common to all members of the species and which increase the probability of death. Ageing is thus the increasing inability to resist death.

Gorman (2000) says, the ageing process is, of course, a biological reality which has its own dynamics, largely beyond human control. However, it is also subject to the constructions by which each society makes sense of old age. In the developed world, chronological time plays a paramount role.

\section{Uniqueness and simplicity in old age people}

Discovery how a small group of committed citizens can come together to support each other in the pursuit of personal happiness and social change for the greater good. The community happiness circle is part of a long tradition of people coming together to change their own lives and create a culture concerned about the common good.

Uniqueness: Somebody singing with a striking voice, or playing with a distinctive tone or touch can convey uniqueness, as can the structure of a song (Bohemian Rhapsody, for example). A painting that clearly identifies the style of its artist or a story written about some unique period of history or place (Harry Potter) can all contribute to a work's uniqueness. An web application that does something that no other application does is also unique, even if imitated later.

Simplicity: When a song has a strong melody, a catchy tune, an unforgettable chorus or some catch phrase in the lyric, it has simplicity. A painting can achieve simplicity through economy of line or through impressionistic brush strokes, or strong composition. A limited colour or tonal range can achieve the same thing. A story can achieve simplicity through language, clear narrative, the choice of simple words, or by having a linear flow or easy to follow story line.

Aliveness: A musical performance or instrumental solo can convey a sense of aliveness just from the touch of the player and the enthusiasm that is conveyed through the musician's playing. A painting can achieve spontaneity through the deftness of the brush strokes, the freshness and immediacy of line and shape or by splashes of contrasting colour, for example. A story can achieve a sense of aliveness through the descriptiveness of the prose or the use of precisely the right words, or by adopting a colloquial tone of voice, perhaps. 


\section{Living with Joy and Balance - Simplicity.}

More and more, people feel that they are working too much, consuming too much, and rushing too much. There is no time for friends and family, no time for community and creativity, any time for a sense of connectedness with the rest of life. The Simplicity movement is a response to this dilemma. It is about living consciously in order to live more fully, thinking through the effects of our behaviors in terms of the consequences for the well-being of people and the planet. It's about asking what's important what matters. It's about redefining the "good life."

The concept of Simplicity is not, as some might think, a life of "self deprivation." It is a turning away from activities that have failed to deliver satisfaction - activities such as shopping and scrambling up the career ladder - in order to embrace activities that bring true joy and meaning - creativity, community, and the celebration of daily life. Simplicity is "the examined life" in which we explore not only what creates fulfillment in our personal lives, but we ask which public policies create societies of justice and environmental well-being. Simplicity touches all aspects of our lives, including the issues of time, work, vocation, community, spending, consuming, health, social justice, and spirituality. Across the country, people are joining simplicity study circles.

The study circle is a small group, peer-led egalitarian form of self education and social change. It's a form of social innovation used extensively in Sweden where study circles are referred to as "education by the people, for the people, and of the people". Sweden has been called a "study circle democracy," and indeed research has found that people who participate in a study circle are apt to be more involved in the common good, regardless of the topic of the study circle. Simplicity study circles are designed to help people discuss the idea of Simplicity and to make concrete changes in their lives. Simplicity study circles are at once a support group, a discussion group, and a method of behavioral change. They focus on building community, creating support for personal change, and engaging in critical thinking for societal change. Topics addressed include Finding More Time, Creating Community, Finding Your Passion, Transforming the Workplace, Reducing Your Consumerism, Creating Healthier Life Styles, Linking Simplicity to Social Justice, Exploring and Defining One’s Spirituality. Simplicity study circles are designed for maximum participation and a minimum of competitiveness within an ethos of acceptance and caring.

People today often experience their lives as lacking vitality or purpose and are looking for the experience of aliveness and depth. Too often people's spirit has been broken; their uniqueness suppressed. By reflecting on their own lives, people can discover their own particular "passion," something they love to do, and something that brings them a sense of direction, a sense of joy and fulfillment, and maybe something from which they can earn money.A basic human need is the experience of community - feeling valued, accepted, cared for and recognized for your true self. Without joyful, exuberant conversation we feel isolated and depressed and pursue the empty paths of shopping and watching television. 


\section{METHODOLOGY}

\section{Statement of the problem}

The effect of age on uniqueness, simplicity and aliveness among old age people

\section{Objectives of the study}

1. To study the uniqueness, simplicity and aliveness among old age men and women.

2. To compare the uniqueness, simplicity, aliveness among old age men and women.

\section{Hypothesis}

H1. There is a significant difference in aliveness, uniqueness, simplicity among old age men and women.

H2. There is a significant difference between uniqueness, simplicity and aliveness among pension and non-pensioned old age people.

\section{Variables}

Dependent variable: old age people.

Independent variable: uniqueness, simplicity and aliveness

\section{Sample size}

A Sample of 210 old age people, are selected for the present study.

The sample consists of 210 old age people from Hassan old age home. In 210, 105 pensioned and 105 non pensioned old age people, the data collected in random method.

Design: quasi experiment design.

Materials: The peak experience scale. Mathes et al., 1982, consists of 70 true - false items.

\section{Statistical analysis}

Statistical techniques used for analysis. The researcher after collecting the data, the data were edited and coded. The data were then analyzed using various statistical tools like, mean, SD and t-test.

\section{DATA ANALYSIS}

Table: 1. Mean, SD and t-value of Aliveness in men and women.

\begin{tabular}{|l|c|c|}
\hline \multicolumn{1}{|c|}{ Group } & Men & Women \\
\hline Mean & 16.20 & 12.68 \\
\hline SD & 2.50 & 2.88 \\
\hline SEM & 0.50 & 0.58 \\
\hline N & 25 & 25 \\
\hline t-value & \multicolumn{2}{|c|}{4.61} \\
\hline p-value & 0.0001 \\
\hline
\end{tabular}

Above table shows Mean, SD and t-value of aliveness in men and women old age people. The mean and SD of men is 16.20 and 2.50. it is score indicates male have higher the aliveness. Than 
the female is 12.68 and 2.88 respectively. Above score indicates that, men have below normal in aliveness and women have very poor in aliveness. It shows that, both have supering from old age aliveness in their daily life. The calculative t-value is 4.61 it is higher the table value 0.001 . the level of significant.

The formulated hypothesis is that "there is significant difference between men and women old age people In their aliveness.” Hence the formulated hypothesis accepted.

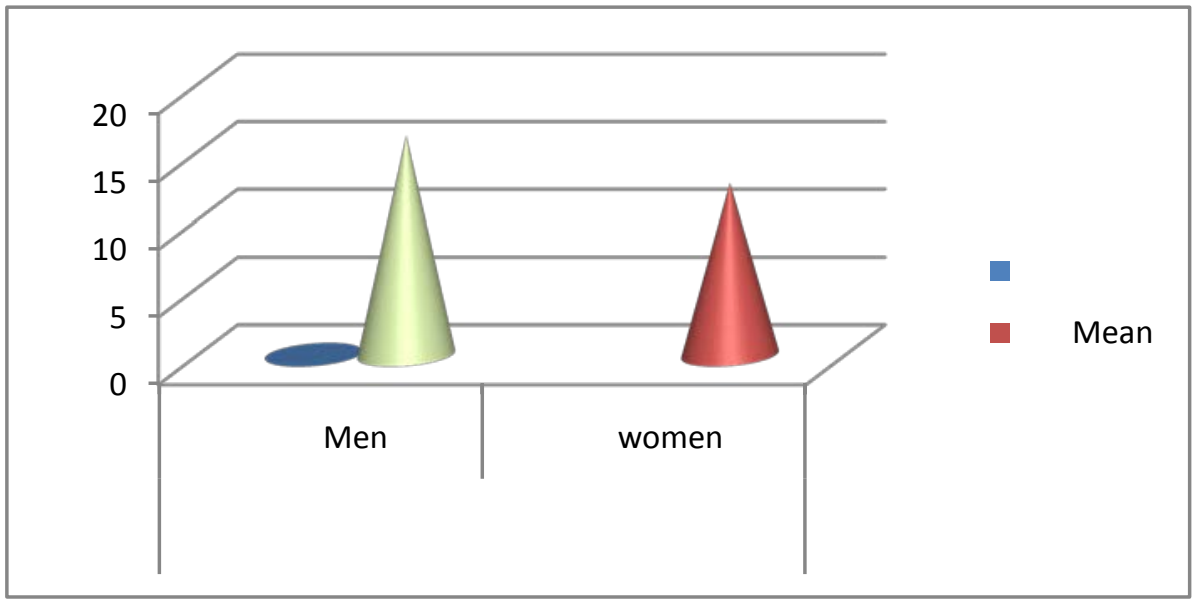

Table:2 Mean, SD and t-value of simplicity in men and women.

\begin{tabular}{|l|c|c|}
\hline \multicolumn{1}{|c|}{ Group } & Men & Women \\
\hline Mean & 13.44 & 10.72 \\
\hline SD & 2.81 & 2.15 \\
\hline SEM & 0.56 & 0.43 \\
\hline N & 25 & 25 \\
\hline t-value & \multicolumn{2}{|c|}{3.54} \\
\hline p-value & \multicolumn{2}{|c|}{0.0005} \\
\hline
\end{tabular}

Above table shows Mean, SD and t-value of Simplicity in men and women old age people. The mean and SD of men is 13.44 and 2.81. it is score indicates male have higher the Simplicity. Than the female is 10.72 and 2.15 respectively. Above score indicates that, men have below normal in Simplicity and women have very poor in Simplicity. It shows that, both have suffering from old age Simplicity in than daily life. The calculative t-value is 3.54 it is higher the table value 0.0005 . the level of significant.

The formulated hypothesis is that "there is significant different between men and women old age people in their Simplicity. Hence the formulated hypothesis accepted. 


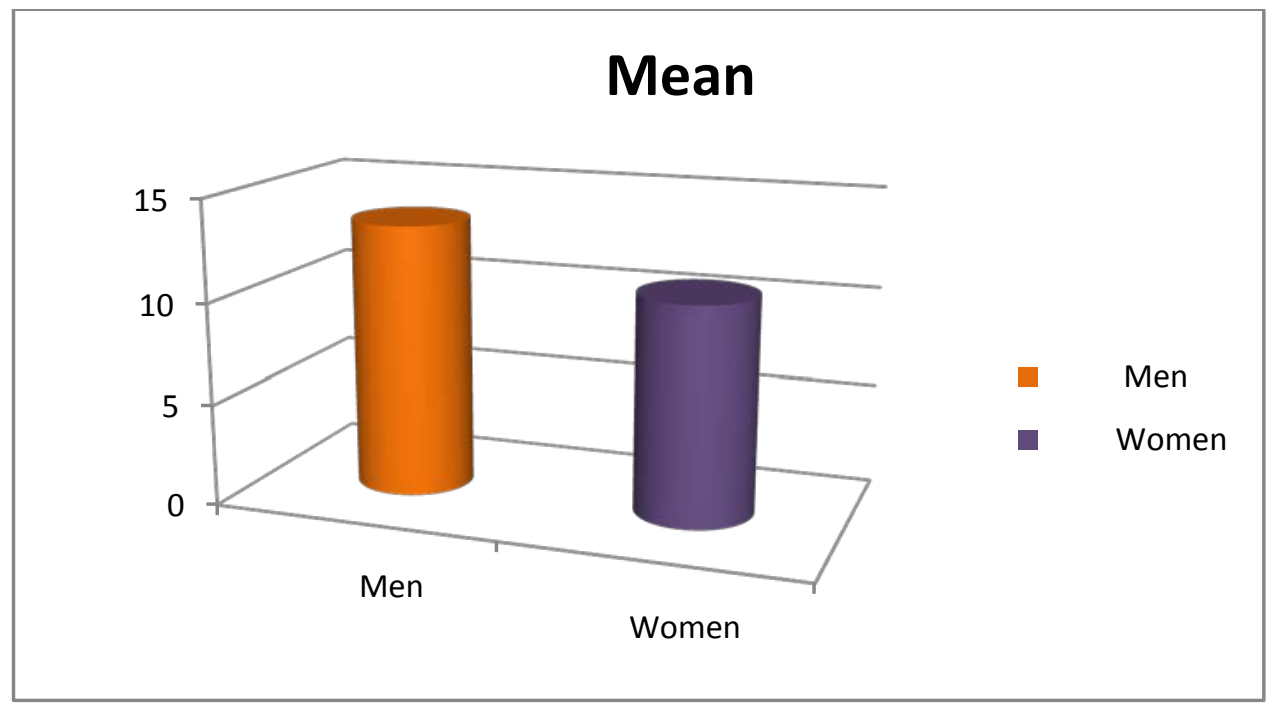

Table:3 Mean, SD and t-value of uniqueness in men and women.

\begin{tabular}{|l|c|c|}
\hline \multicolumn{1}{|c|}{ Group } & Men & Women \\
\hline Mean & 9.72 & 13.44 \\
\hline SD & 4.92 & 2.81 \\
\hline SEM & 0.98 & 0.56 \\
\hline N & 25 & 25 \\
\hline t-value & \multicolumn{2}{|c|}{3.2812} \\
\hline p-value & \multicolumn{2}{|c|}{0.0001} \\
\hline
\end{tabular}

Above table shows Mean, SD and t-value of uniqueness in men and women old age people. The mean and SD of men is 9.72 and 4.92. it is indicates female have higher the uniqueness. Than the female is 13.44 and 2.81 respectively. Above score indicates that, men have below normal in uniqueness and women have very poor in uniqueness. It shows that, both have sparing from old age uniqueness in their daily life. The calculative t-value is 3.2812 it is higher the table value 0.0001 level of significant.

The formulated hypothesis is that "there is significant different between men and women old age people In their uniqueness.” Hence the formulated hypothesis accepted.

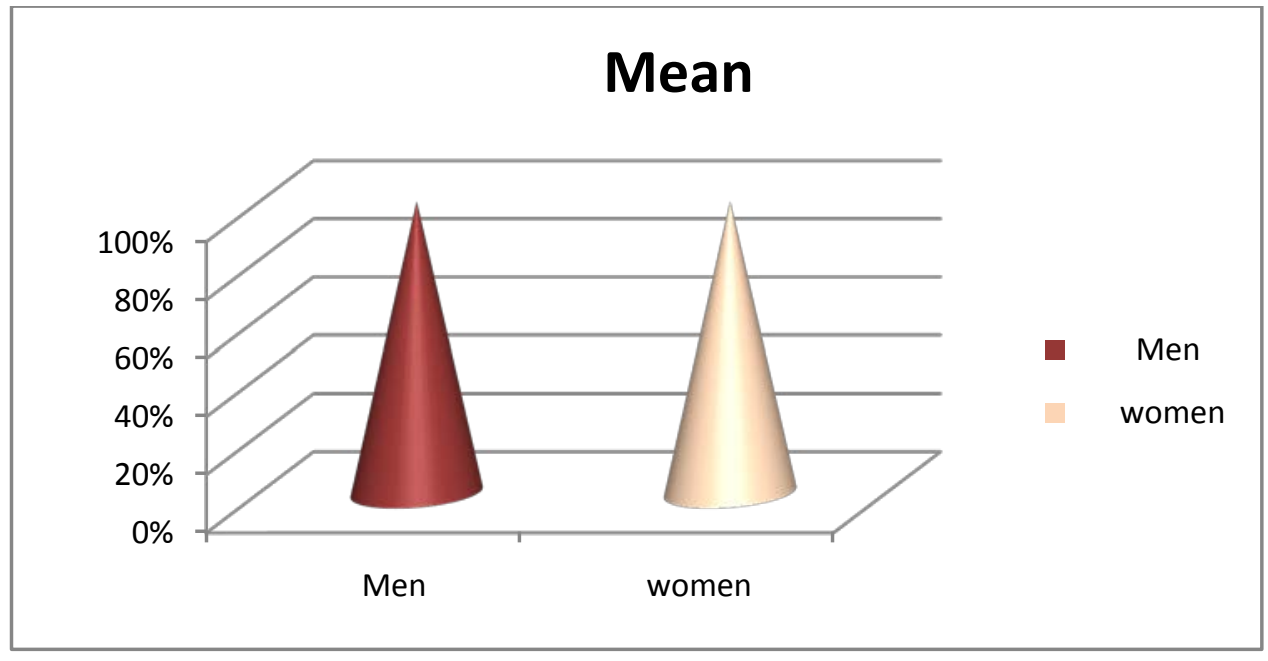


Table:4 Peak Experience in men and women

\begin{tabular}{|l|l|l|l|l|}
\multicolumn{2}{l}{ Pension } & \multicolumn{1}{c|}{ non-pension } & \multicolumn{1}{c|}{ Women } \\
\hline \multicolumn{1}{|c|}{ Group } & \multicolumn{1}{c|}{ Men } & Women & \multicolumn{1}{c|}{ Men } & 31.47 \\
\hline Mean & 41.60 & 37.60 & 41.27 & 11.06 \\
\hline SD & 4.45 & 6.41 & 4.01 & 2.86 \\
\hline SEM & 1.15 & 1.66 & 1.03 & 15 \\
\hline N & 15 & 15 & 15 & \\
\hline t-value & 1.9517 & & 3.22 & \\
\hline p-value & 0.05 & 0.001 & \\
\hline
\end{tabular}

Above table shows Mean, SD and t value of pension and non pension in men and women old age people. The pension mean and SD of mean is 41.60 and 4.45. it is score indicates men have higher the peak experience. Than the female is 37.60 and 6.41respectively. above score indicates that men have below normal in peak experience and women have very poor in peak experience. It shows that, both have sparing from old age peak experience in their daily life. The calculative t-value is 1.9517 it is higher the table value 0.005 level of significant.

The non pension mean and SD of mean is 41.27 and 4.01. it is score indicates men have higher the peak experience. Than the female is 31.47 and 11.06. Respectively Above score indicates that men have below normal in peak experience and women have very poor in peak experience. It shows that, both have sparing from old age peak experience in their daily life. The calculative t-value is 3.22 it is higher the table value 0.001 level of significant.

The formulated hypothesis is that "there is significant difference between men and women old age people. In their peak experience”. Hence the formulated hypothesis accepted.

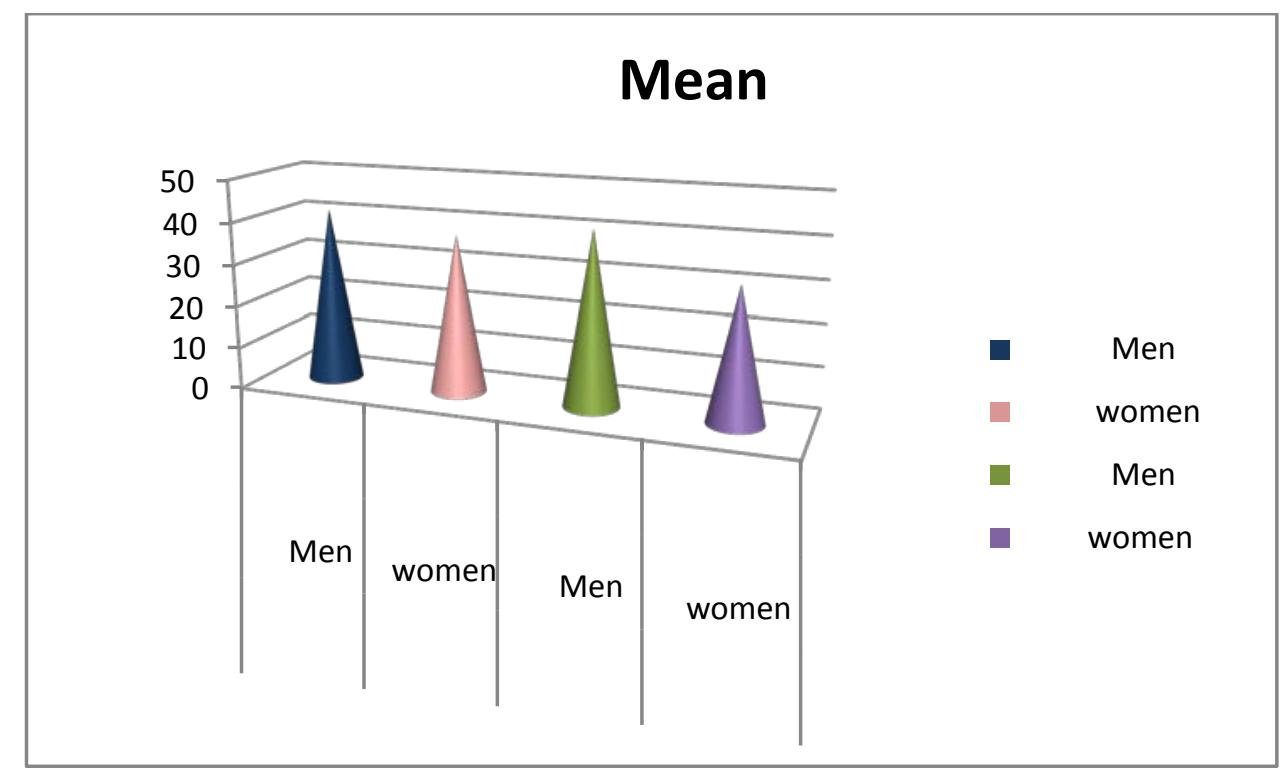




\section{SUMMARY AND CONCLUSION}

- There is significant difference between men and women old age people in their aliveness.

- The score indicates that men have below normal in aliveness and women have very poor in aliveness in their daily life.

- There is significant different between men and women old age people in their simplicity.

- The score indicates that, men have below normal in simplicity and women have very poor in simplicity in their daily life.

- There is significant difference between men and women old age people in their uniqueness.

- The score indicates that, men have below normal in uniqueness and women have very poor in uniqueness in their daily life.

- There is significant difference between pensioned and non-pensioned old age people in their peak experience.

- The pension score indicates that men have below normal in peak experience and women have very poor in peak experience in their daily life.

- The non-pension score indicates that men have below normal in peak experience and women have very poor in peak experience in their daily life.

\section{REFERENCE}

Allen, R. M., Haupt, T. D., \& Jones, R. W. (1964). Analysis of peak experiences reportedby college students. Journal of Clinical Psychology, 20, 207-212.

Atkins, C. (1990). A comparative analysis of peak experience performance and non-peak experience performance in professional actors and actresses. (Doctoral dissertation, United States International University) Dissertation Abstracts International, 5104B,2096. (UnM9025205).

Bakker, A. B. (2005). Flow among music teachers and their students: The crossover of peak experience. Journal of Vocational Behavior, 66(1), 26-44...

Bradach, K. M. (1990). The direct and trans generational effects of traumatic death on family functioning and adolescents' individuation. Unpublished Doctoral Dissertation, Boston University.

DeMares, R. (1999). Peak experiences with cetaceans: A phenomenological study. Unpublished doctoral dissertation, The Union Institute.

DeMares, R., \& Krycka, K. (1998). Wild-animal-triggered peak experience: Transpersonal aspects. Journal of Transpersonal Psychology, 30(2), 161-177.

Diener, E., Suh, E. M., Lucas, R. E., \& Smith, H. L. (1999). Subjective well-being: Three decades of progress. Psychological Bulletin, 125(2), 276-302.

Ebersole, P. (1972). Effects of classifications of peak experiences. Psychological Reports, 30, 631-635..

Fredrick, M. J. (1999). Peak moments in sport karate tournament competition: Black belt fighters in the zone. Unpublished doctoral dissertation, University of Utah.

Handbook. NY: Bruner/Maze. 


\section{The Effect of Age on Uniqueness, Simplicity and Aliveness among Old Age People}

Heery, B. P. (2003). Awakening spirit in the body: A heuristic exploration of peak or mystical experience in the practice of Aikido. Unpublished doctoral dissertation, Institute of Transpersonal Psychology.

Hollander, D. B., \& Acevedo, E. O. (2000). Successful English Channel swimming: The peak experience. Sport Psychologist, 14(1), 1-16.

Janoff-Bulman, R., \& Berger, A. R. (2000). The other side of trauma: Towards a psychology of appreciation. In J. Harvey \& E. D. Miller (Eds.), Loss and Trauma

Lavaysse, L. M. (2003). Professional singers describe peak experiences that arise during public performances. Unpublished doctoral dissertation, California Institute of Integral Studies.

Leach, D. (1962). Meaning and correlates of peak experience. Doctoral dissertation, University of Florida. (Dissertation Abstract International, 1963, 24-01, 180, University Microfilms No. 6302674)

Lowis, M. J. (2002). Music as a trigger for peak experiences among a college staff population. Creativity Research Journal, 14(3-4), 351-359.

Maslow, A. H. (1964). Religions, values, and peak-experiences. New York: Penguin.

Mathes, E. W., Zevon, M. A., Roter, P. M, \& Joerger, S. M. (1982). Peak experience tendencies: Scale development and theory testing. Journal of Humanistic Psychology, 22(3), 92-108. 